effects on cardiovascular smooth muscle, for example, may be intimately related to the important anti-hypertensive role of the kidney. Prostaglandins also suppress lipolysis in adipose tissues, and potently antagonize the actions of various lipolytic hormones. The mechanism of prostaglandin action in adipose tissue suggests that they may play a part of fundamental importance in many hormone responsive tissues, for they have been found to interact directly with the adenyl cyclase- $3^{\prime} 5^{\prime}$-AMP system which is coming increasingly into prominence as the target mechanism underlying the actions of many different hormones.

In addition prostaglandins have direct effects on the electrical activity of neurones in the central nervous system. An increased efflux of prostaglandins may be evoked from many tissues, including the cerebral cortex, by neural, drug or hormone stimulation. Although it seems unlikely that prostaglandins themselves are released as nerve transmitter substances, they may well prove to be intimately involved in the responses of innervated tissues to nerve transmitter substances, or in the responses of target organs to hormones.

This field of research seems certain to remain a fertile one for many years to come. The book is extremely well edited and produced. Despite the astronomical cost, it is thoroughly recommended to all who wish to know more about this lively area of research.

L. L. IVERSEN

\section{DRUGS AND THE MIND}

\section{Psychopharmacological Agents,}

Vol 2. (Medicina] Chemistry: a Series of Monographs, Vol. 4-2.) Edited by Maxwell Gordon. Pp. xviii +622. (New York: Academic Press, Inc.; London: Academic Press, Inc. (London), Ltd., 1967.) $200 s$.

THE magnitude and importance of research into psychopharmacological agents is reflected in the necessity for two volumes to cover this field whereas most of the companion monographs in this series dealing with other areas of medicinal chemistry required but one.

The phenothiazone chapter was so disproportionately long ( 161 pages) that to include it in a single volume with the other topies (now in the first volume) would have produced a book of unmanageable size. This chapter now forms about one quarter of the second volume. Even in 161 pages, only the more important published work in the phenothiazine field has been included. The references to papers quoted in this chapter fill thirty-seven pages but Dr Gordon is commendably modest about his additional bibliographies of the other individual phenothiazine compounds and of meprobamate-like agents which occupy no less than 202 pages and provide an outstandingly valuable source. It is seldom that such a service is done to the student of a subject.

At the feet of the gigantic contribution on phenothiazine agents are a series of mini-reviews. Paul A. J. Janssen discusses haloperidol and the related butyrophenones (thirty-two pages). This is followed by a consideration of the biochemical basis of mental discase (twenty-eight pages) by Louise H. Greenberg, R. F. J. McCandless and Maxwell Gordon. The latter, who is the editor of the volume, has also compiled a useful list of miscellaneous psychotherapeutic agents giving structural formulae, non-proprietary and proprietary names together with the manufacturer, the medical use and references for each.

Turning to the individual review articles, the chapter on phenothiazine opens with a list of clinically-used phenothiazines with their structural formulae and alternative trade names. It recalls that the phenothiazine structure was christened thiodiphenylamine by Bernthsen in 1883, when he employed thionation as the first synthetic method, and this still survives in the present-day synthesis of some phenothiazine agents. Illustrated by structural formulae, the synthesis of first, clinically-useful and then other miscellaneous phenothiazines follows. The pharmacological techniques used to screen for tranquillizing actions are outlined for the non-pharmacologist.

The pharmacological effects of the phenothiazine drugs on the various body systems in experimental animals is comprehensively covered, but the main attention is focused on chlorpromazine because of the volume of work carried out on this compound, the first and still a most important member of the series of major tranquillizing drugs. 'The author stresses the paucity of effort, probably due to the scarcity of clinical pharmacologists, directed to the assessment of psychotherapeutic agents in man. It seems a pity that recent work in this field has not been included, to indicate a shift in emphasis to quantitative human pharmacology. Although knowing the difficulties and delays in getting reviews to press, I find it a little disappointing to note that this roview on the classical phenothiazine, ehlorpromazine, should include only a few references as recent as 1965 and none more recent.

In the second chapter, Janssen reviews his work on the 4-phenyl-piperidine compounds, which are related chemically to pethidine and which show mixed morphinelike and chlorpromazine-like actions. Others of the related compounds have typical chlorpromazine-like actions and seem devoid of morphine-like effects. The introduction of a fluorine action in the para-position on the ketone ring and a halogen group on the other ring enhanced tranquillizing potency. One of these was haloperidol, which has been studied pharmacologically and in psychiatry. A number of clinical reports of the effects of haloperidol and its analogues are quoted, but only a handful are controlled double blind clinical trials. It will be several years before the role of haloperidol and its co-genors can be determined in man but these compounds represent a fascinating new addition to the psychotherapeutic armamentorium.

The opening paragraph of the chapter on the hiochemical basis for mental disease is worthy of framing and of hanging at the entrance to every laboratory concerned with synthesis of or research on drugs to alleviate mental illness. It stresses that success in this field has been accidental and does not stem from an understanding of the biochemical fundamentals which still elude us.

This volume will be useful to the medicinal chemist and biochemist, to the pharmacologist and the physiologist, to the clinical pharmacologist and the clinician, who may all be interested in the synthesis, structure-action relationships and the effects of phenothiazine agents.

\section{J. P. Quilliam}

\section{WORKING OF THE BRAIN}

\section{Integrative Activity of the Brain}

An interdiseiplinary Approach. By Jerzy Konorski. Pp. xii +531 . (Chicago and London: University of Chicago Press, 1967.) $135 s$.

IN any prolonged history of research in a field as complex as the workings of the vertebrate brain, the concepts and models which are essential before any problems can be formulated become so resistant to change that they may finally come to hamper progress rather than to help it. One very salutary way of testing accepted ideas is to examine with care the approach to the same problems made by someone from a quite different school of thought. Professor Konorski has so extended his earlier and very influential formulations of neo-Pavlovian theory, that his new book will provide just such an opportunity for a great many people.

It must be admitted that a certain amount of hard work is necessary in order to master a terminology, much of which is new, and in itself of interest only to reflex 